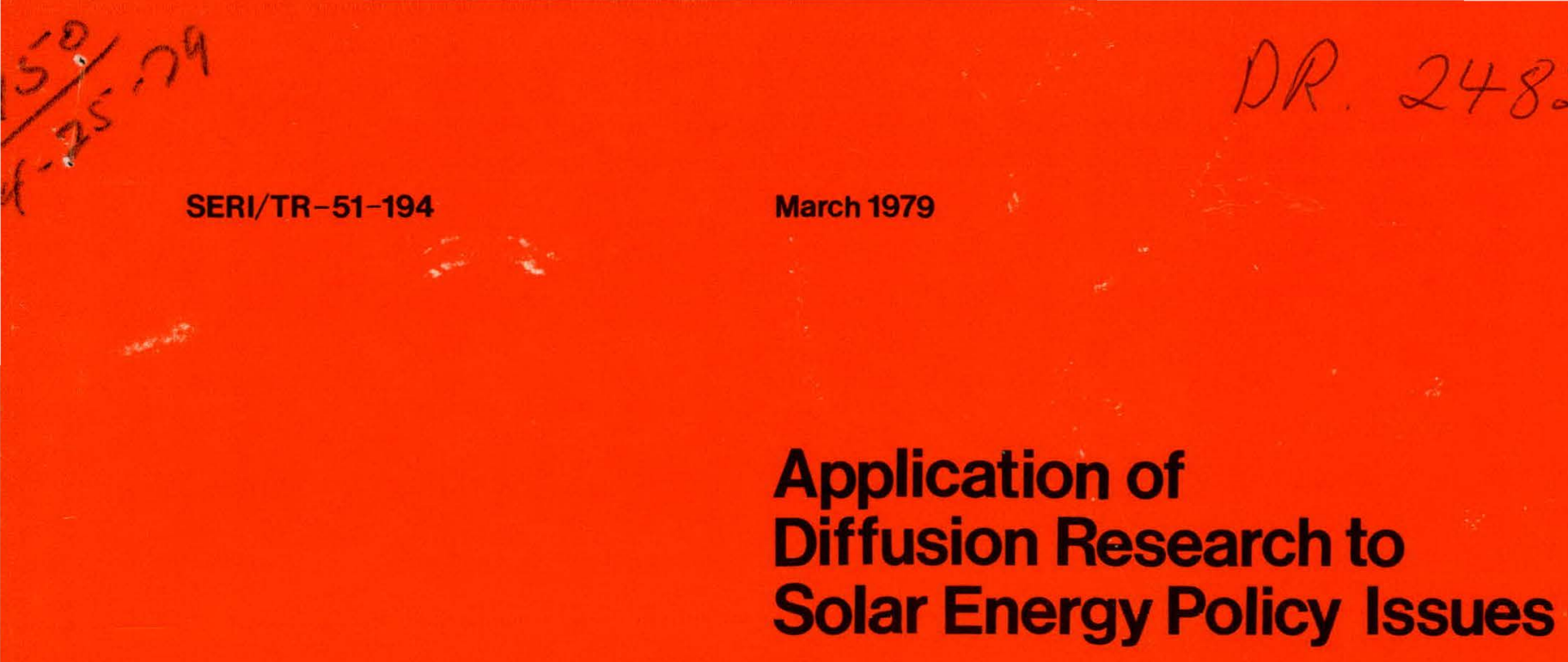

\title{
Application of Diffusion Research to Solar Energy Policy Issues
}

J. David Roessner

David Posner

Floyd Shoemaker Avraham Shama
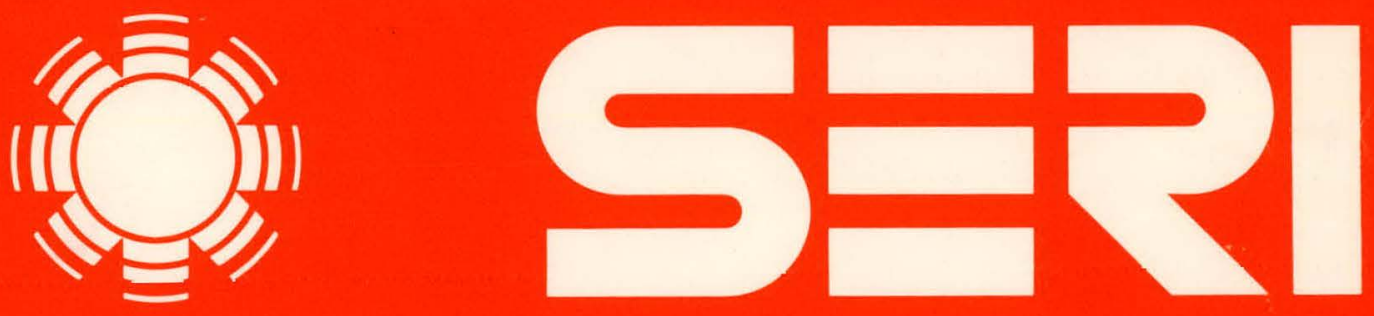

Solar Energy Research Institute

A Division of Midwest Research Institute

1536 Cole Boulevard

Golden, Colorado 80401

Operated for the U.S. Department of Energy under Contract No. EG-77-C-01-4042
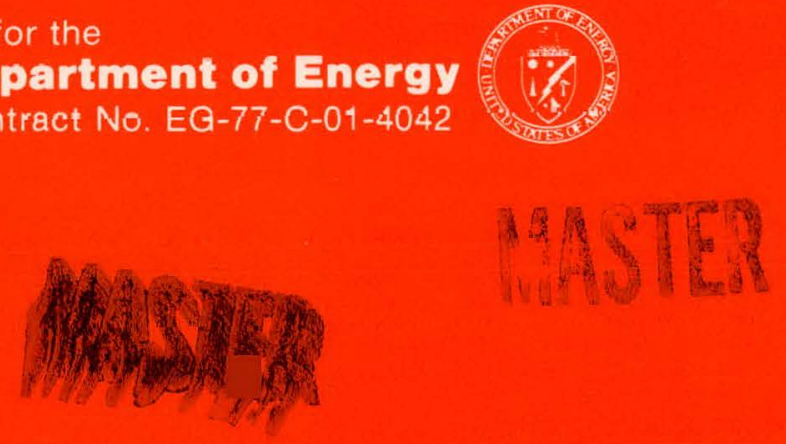


\section{DISCLAIMER}

This report was prepared as an account of work sponsored by an agency of the United States Government. Neither the United States Government nor any agency Thereof, nor any of their employees, makes any warranty, express or implied, or assumes any legal liability or responsibility for the accuracy, completeness, or usefulness of any information, apparatus, product, or process disclosed, or represents that its use would not infringe privately owned rights. Reference herein to any specific commercial product, process, or service by trade name, trademark, manufacturer, or otherwise does not necessarily constitute or imply its endorsement, recommendation, or favoring by the United States Government or any agency thereof. The views and opinions of authors expressed herein do not necessarily state or reflect those of the United States Government or any agency thereof. 


\section{DISCLAIMER}

Portions of this document may be illegible in electronic image products. Images are produced from the best available original document. 
NUTYCE

This report was prepared as an accuuni of work sponsored by the United States Government. Neither the United States nor the United States Department of Energy, nor any of their employees, nor any of their contractors, subcontractors, or their employees, makes any warranty, express or implied, or assumes any legal liability or responsibility for the accuracy, completeness or usefulness of any information, apparatus, product or process disclosed, or represents that its use would not infringe privately owned rights. 
J. DAVID ROESSNER

DAVID POSNER

FLOYD SHOEMAKER

AVRAHAM SHAMA

MARCH 1979

\section{Solar Energy Research Institute}

$15366^{\circ}$ Cole Boulevard

Golden, Colorado 80401

This repont was prepared as an accoutnt of work sponsored by the United States Government. Neither the United States nor the United States Department of Enerdy, nor any of their employes, nor any of the Exys contractors, subcontractors, or theis employees, makes any warranty, express or implied, or assumes any legal lisbiliy or responsibity for the accuracy, completeress or usefuntess of any information, apparatus, product or process disclnosed, of represents that its use womld nn infringe privately owned rights.

A Division of Midwest Research Institute

Prepared for the

U.S. Department of Energy

Contract No. EG.77.C.01.4042 


\section{FOREWORD}

This report was prepared in response to a request from the Office of Planning and Technology Transfer, Division of Energy Technology of the U.S. Department of Energy (DOE). The report describes the relevance of research on the diffusion of solar energy systems to policy issues confronting DOE solar energy programs. Policy issues related to both the technology development problems faced by Energy Technology (DOE) and to solar energy commercialization problems faced by Conservation and Solar Applications (DOE) are considered.

The leader for the project was J. David Roessner of SERI's Policy Analysis Branch. Other authors from the Policy Analysis Branch are David Posner and Avraham Shama. Floyd Shoemaker, Communications Branch, contributed to the Communication research.

The authors acknowledge the helpful comments on the report offered by Melvin Simmons and Barbara Farhar of SERI; and R. Bruce Hutton and Dennis McNeill of the College of Business Administration, University of Denver.

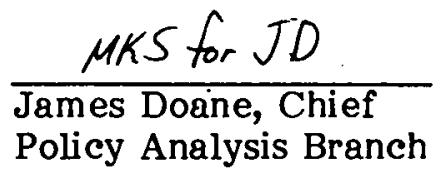

Approved for:

SOLAR ENERGY RESEARCH INSTITUTE

Melvin K. Simmons, Assistant Director Analysis and Assessment Division 


\section{TABLE OF CONTENTS}

Page

1.0 Introduction $\ldots \ldots \ldots \ldots \ldots \ldots \ldots \ldots \ldots \ldots \ldots \ldots \ldots \ldots$

2.0 Solar Energy Policy Issues and Diffusion

Questions

2.1 Cost Reduction and Performance

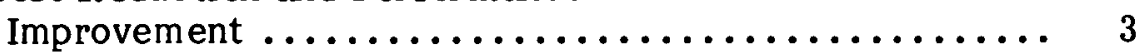

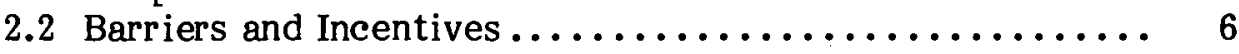

3.0. Diffusion Research: An Overview $\ldots \ldots \ldots \ldots \ldots \ldots \ldots \ldots$

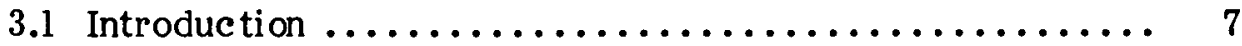

3.2 Key Findings and Generalizations ............... 8

3.3 Summary Assess ment and Conclusions ............ 10

4.0 Communication Research $\ldots \ldots \ldots \ldots \ldots \ldots \ldots \ldots \ldots \ldots$

4.1 Introduction $\ldots \ldots \ldots \ldots \ldots \ldots \ldots \ldots \ldots \ldots \ldots \ldots \ldots \ldots$

4.2 Key Findings and Generalizations ............... 13

4.3 Summary Assessment and Conclusions .............. 14

5.0 Marketing and Consumer Research $\ldots \ldots \ldots \ldots \ldots \ldots \ldots \ldots$

5.1 Introduction $\ldots \ldots \ldots \ldots \ldots \ldots \ldots \ldots \ldots \ldots \ldots \ldots \ldots$

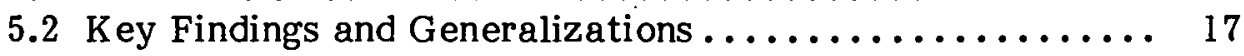

5.3 Summary Assessment and Conclusions ............. 19

6.0 Solar Energy Market Penetration Models .............. 21

7.0. Applications of Diffusion Research to Solar

Energy Policy Decisions ....................... 23

7.1 Allocation of $R \& D$ Budgets ................. 23

7.2 Assessment of Alternative Intervention

Strategies ............................ 23

8.0 Summary and Recommendations................. 25

$9.0 \quad$ References............................ 27

\section{LIST OF TABLES}

2-1 Energy Policy Issues and Related Diffusion Questions 


\section{SECTION 1.0}

\section{NTTRODUCTION}

Since their inception, federal government solar energy programs have recognized that the ultimate measure of their success is the amount of energy produced by solar energy systems. Concern for energy production potential has pervaded U.S. Department of Energy (DOE) technology development programs. Those technologies which show the greatest potential for producing significant quantities of energy at prices that would be competitive in the private market are, at least in part, the technologies most favored by DOE.* These are the technologies that should yield new sources of energy supplies or result in energy conservation.

An important DOE policy problem is to estimate the extent to which competing technologies will be successful in the private market. Federal solar programs also have recognized that developing a technology to the point near which it is economically competitive in the private market is not sufficient to ensure that the technology will begin to make an energy contribution. Accelerated commercialization-an eff ort to increase the rate at which solar energy technologies are adopted-has been and is a basic component of the federal solar energy approach. In attempting to accelerate solar energy commercialization, DOE must develop programs that enhance solar energy market acceptance. To do this effectively, it is necessary to understand the factors that influence decisions between alternative energy technologies by appropriate decision makers in the market, and to understand how these decisions can be influenced by government action. However, estimates of the market impacts of government programs are, by themselves, inadequate measures of a program's social costs and benefits. Market impacts must be translated into broader social measures to make meaningful policy comparisons between competing programs.

This paper examines two types of information requirements which appear to be basic to DOE solar energy policy decisions:

1. How can the future market success of solar energy technologies be estimated?

2. What factors influence the adoption of solar energy technologies, and what specific programs could promote solar energy adoption most eff ectively?

This paper assesses the ability of a body of research, referred to here as diffusion research, to supply infor mation that could partially satisfy these requirements.

There is a lot of diffusion research around. A recent bibliography on the diffusion of innovations listed over 3,000 publications "which deal with an innovation and how it is communicated through certain channels over time among the members of a social system" [1]. Diffusi on research began in the 1930s, expanded rapidly during the 1950s, and continues to expand. A recent assessment of diffusion research states, "Few fields of social science research have received so much attention by scholars for so many years" [2]. Government agencies have funded diffusion research because this approach

*Other factors such as environmental and health impacts of a technology also enter into priority decisions. 
promises a way of getting research results used and "best practices" adopted. Examples include the Department of Agriculture's Cooperative Extension Service, the National Institute of Health's research on technological diffusion among hospitals, the Agency for International Development's efforts to diffuse family planning techniques, and the National Institute of Education's research on educational innovation diffusion among public schools. Researchers from a variety of social science disciplines have applied diffusion methods to questions of social change, economic growth, organizational change, market research, and behavioral change.

Despite the abundance of diffusion research, some federal programs can be described as diffusion failures. For example, the disappointing results of the U.S. Department of Housing and Urban Development's Operation Breakthrough effort to encourage the development and use of industrialized housing techniques have been partially attributed to an inadequate understanding of the dynamics of the housing industry and market [3]. IInd more resnurress been devoted to analysis of how the new housing concepts under development would be received by the industry and markot, the results of the program may have beerr more rapidly and widely accepted.

Government-sponsored programs that intend to develop new technologies for use in the private sector are usually undertaken at substantial cost. If analyses of how private decision makers will respond to these new technologies can improve the effectiveness of technology development programs, then the modest cost of these analyses are a worthwhile investment. This paper contends that diffusion studies can provide information useful to DOE in resolving solar energy policy issues and in designing effective solar energy programs.

This assessment proceeds, flrst, by defining in greater detail a series of policy issues that face DOE. These are divided into cost reduction and performance improvement issues which include issues confronting the technology development component of the solut energy program, and barriers and incentives issues which are most relevant to problems of solar energy application. Second, these issues are trunslated into a series of questions that the diffusion approach can help resolve. Third, various elements within diffusion research are assessed in terms of their abilities to answer policy questions. Finally, the strengths and limitations of current knowledge about the diffusion of innovations are summarized, the applicability of both existing knowledge and the diffusion approach to the identified solar energy policy issues are discussed, and ways are suggested in which diffusion approaches can be modified and existing knowledge employed to meet shortand long-term goals of DOE. Our inquiry covers the field of "classical" diffusion research (defined above), market research and consumer behavior, communication research, and solar energy market penetration modeling. 


\section{SECTION 2.0}

\section{SOLAR ENERGY POLICY ISSUES AND DIFFUSION QUESTIONS}

Table 2-1 presents a series of policy issues which confront managers of both programs for solar energy $R \& D$ and programs to accelerate solar energy commercialization. Parallel to these issues, questions which require knowledge of the rate and process of solar energy diffusion are presented. These issues and questions suggest that analyses of many DOE solar energy policy problems could benefit by the application of diffusion research.

\subsection{COST REDUCTION AND PERFORMANCE IMPROVEMENT}

Solar energy research and development (R\&D) programs have as their primary objectives reduction in costs and improvement in performance of particular solar energy technologies. Cost reductions and performance improvements are desirable because they make the technologies more economically competitive in potential markets. Many solar energy programs have established technology cost goals which identify the costs that would make solar systems competitive with other energy sources. Solar R\&D programs are designed to produce technologies with economic and performance characteristics which will lead to widespread diffusion in private markets.

Within DOE solar energy programs, numerous technologies and approaches to reduce cost and improve performance compete for $R \& D$ funds. Estimates of the energy contributions that can be expected from each solar technology and when these contributions will be delivered are considered to be fundamental to the budget allocation process. Diffusion research may be capable of improving the credibility of previous eff orts to project solar energy market penetration. For example, several factors in addition to cost are known to influence the diffusion rate of a new technology. Yet, market penetration analyses of solar energy to date treat cost as the only important factor. As discussed in later sections of this paper, diffusion research could identify other factors which affect solar energy adoption and determine their significance. In addition to being useful for making market penetration estimates, this information could also help specify other requirements that technologies must meet to achieve market success.

Information on the expected rate of diffusion for various solar energy technologics is not, by itself, very useful for the development of the solar $R \& D$ budget. However, if different $R \& D$ budget allocations are expected to result in different future technology performance and cost characteristics, then diffusion research could supply insights into the market responses to these characteristics. The $R \& D$ costs required to make improvements in one solar technology may be very high in comparison to the positive impact that the improvements would have on market decisionmakers. $R \& D$ funds might be better spent on programs which would result in greater diffusion for available dollars.

The effectiveness of cost reduction strategies such as public procurement is dependent on how rapidly solar technologies are adopted. Economies of scale in production, for example, may yield unit cost reductions. When DOE cost reduction strategies and cost expectations depend on economies of scale and production experience, then the capability of the market to support production rates and provide production experience needs to be exumined, 
Table 2-1.

ENERGY POLICY ISSUES AND RELATED DIFFUSICN QUESTIONS

DIFFUSION-RELATED QUESTIONS

\section{POLICY ISSUES}

\section{Cost Reduction and Performance Improvement}

1. If specified cost and perfor mance goals for solar energy technologies are achieved, what amount of energy could each technology produce

2. If different research and development budget allocations are expected to result in different future technolagy performance and cost characteristics, which allocations will result in the greatest diffusion?

3. How will the diffusion rate affect the success of cost reduction strategies such as government procurement, which are designed to reduce cost through increases in production rates and accumulated production experience? in the future?

1. What effect do cost and performance have on the diffusion o: solar energy technologies?

2. What factcrs other than cost and performance affect the rate of diffusion?

3. What is the relative significance of cost, performance, and other factors on the rate of diffusion of solar technologies?

4. How can the many factors that affect diffusion be combined to estimate future solar energy market penetration?

5. How accurately can data collected during early stages of diffusion predict the ultimate pattern and rate of diffusion?

6. Will government and private purchases of a technology be sufficient to permit economies of scale in production?

7. Will reductions in price lead to increases in private purchases that will cause further cost reductions attributable to accumulated industry experience?

\section{Barriers and Incentives}

1. What incentive strategies are most likely to be effective in accelerating the diffusion rates of solar energy technologies?

2. How should specific incentive programs such as information dissemination or demonstrations be designed and implemented?
1. What is the relative significance of particular barriers to solar energy diffusion?

2. What will be the effect of alternative incentive options upon these barriers and the diffusion rate of a particular technology? 


\section{POLICY ISSUES}

\section{Barriers and Incentives (con't)}

3. What is the appropriate balance between government actions to further improve cost and per-ormance, and actions to stimulate adoption of existing systems?

4. How is this balance to be determined on a technology-specific basis?

\section{DIFF USION-RELATED QUESTIONS}

3. To what extent do selected incentives work together to simultaneously reduce barriers and increase diffusion?

4. How is information exchanged in specific market sectors?

5. What types of demonstration projects could be successful in reducing uncertainty, how many projects are needed, and where should they be located?

6. To what extent is lack of information delaying use of solar energy?

7. What kinds of information would best assist different groups in using solar energy? 


\subsection{BARRIERS AND INCENTIVES}

For these kinds of issues, technological cost and performance goals largely have been achieved. The technology is assumed to be ready for market introduction, and government actions are directed toward developing strategies other than cost reduction or performance improvement that will speed the adoption and use of the technology. Demand for the technology can be increased through financial incentives; uncertainty or ignorance among potential consumers can be reduced through demonstrations, information dissemination, or product certification and warrantees; institutional barriers, such as resistance among lending institutions, and lack of trained installation and maintenance personnel can be addressed through incentives, information dissemination, and education campaigns.

'l'he challenges for public policy include: (1) corrently idcntifying the problem that impedes technology diffusion or market penetration; (2) selecting the stratcgy or mix of strategies appropriate to the problem; and (3) designing and implementing programs that will be effective in each particular technology and market setting. As in the case of $R \& D$ programs, DOE budget allocation decisions depend upon estimates of the relative success of alternative strategies or strategy mixes for each technology, since the proportion of national energy produced by target technologies will depend upon the extent of their penetration into the market. An understanding of the diffusion process is, therefore, essential for developing effective strategies and predicting their impacts on market acceptance. 


\section{SECTION 3.0}

\section{DIPFUSION RESEARCH: AN OVERVIEW}

\subsection{INTRODUCTION}

The scope of the diffusion literature is vast.* One recent, comprehensive review of the literature searched 39 journals that covered the fields of management, political science, sociology, public administration, business administration, planning, urban studies, operations research, policy research, and economics [4]. Focusing on the diffusion of technology, unfortunately, does not limit the scope of potentially relevant works because no one yet has determined the limits of applicability of research on nontechnological diffusion (new ideas, programs, analytic techniques, organizational arrangements) to problems of technology diffusion (new products and processes). Thus, while it is relatively easy to identify national policy issues that involve the diffusion of technology, one cannot exclude studies of the diffusion of nontechnological innovations from the reservoir of potentially relevant literature.

A number of recent, critical syntheses of the diffusion literature offer some useful ways to categorize the literature and provide an overview of its contents. Brown, in a recent paper that emphasizes how different disciplinary approaches lead to consideration of different leverage points for policy action, discusses four perspectives on diffusion research [5] :

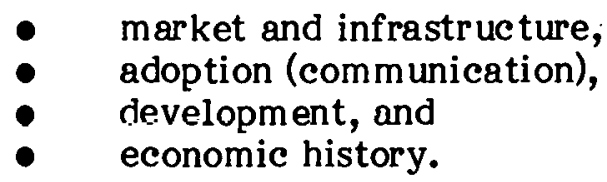

The adoption or communication perspective stresses the communication channels through which information about innovations is transmitted. The attributes of potential adopters and the structure and operation of communication channels largely explain diffusion outcomes. The market and infrastructure perspective shif ts emphasis to the supply of innovations, strategies for stimulating demand, and the context of the diffusion process. Here, the focus is on logistics, distribution, and the promotion of innovation rather than on adopter behavior. Economic historians take an evolutionary perspective, emphasizing how innovations themselves change during the process of diffusion and on how social and economic structures mutually adapt to the innovation as it diffuses. The development perspective is concerned almost exclusively with innovation diffusion in developing nations. It raises the question of who benefits from diffusion and addresses distributional and equity issues.

Kelly and Kranzberg discuss three traditions in diffusion research, each defined by similarities in the conceptual structure employed and the variables chosen for primary consideration [6]. The spatial diffusion (geographic) tradition originally focused almost exclusively on the patterns of spread of innovations and on the learning processes

*Following common practice, the diffusion literature includes research on the factors that influence the adoption of innovations by individuals and collectivities as well as research on the factors that influence the speed and shape of the spread of innovations throughout a population. 
involved, but more recently has incorporated market factors such as the role of propagators. The economic perspective singles out cost-related features of innovations such as profitability, economic advantage, and cost to explain innovation diffusion. The social-psychological tradition seeks to understand the reasons for resistance to innovation and change. It explores the nature of relative advantage and resistance to change as determined by social, cultural, and psychological components. In this tradition, social networks appear as prominent explainers of innovation diffusion.

Yin, drawing up on earlier work by Havelock, distinguishes four traditional approaches for studying the innovative process: research, development, and diffusion; social interaction; innovative organizations; and organizational change [7]. The research, development, and diffusion approach encompasses the range of institutions involved in the process of innovation from basic research through development to diffusion, adoption, and use. It tends to view the process as linear and places relatively little emphasis on adoption and use prornsses. The social interaction approach is the "classic" diffusion approach. It focuses on communication processes among sucial networks and views diffusion as a process of learning among individuals. The innovative organizations approach is a static one, attempting to identify those organizational attributes that differentiate innovative from noninnovative organizations. Finally, the organizational change approach, as the name implies, focuses on change processes within the organization, viewing innovation as only one type of change. As in Yin's latter two categories, Havelock's "problem solving" approach focuses on processes within the organization and emphasizes potential adopter needs as the driving force in innovation [8].

\subsection{KEY FINDINGS AND GENERALIZATIONS}

Summaries and syntheses of the diffusion literature reveal that diffusion researchers have been successful in identifying influential factors in innovation diffusion-individual-, organizational-, environmental-, and innovation-related. The characteristics of individuals likely to adopt InIuvulions carlion than nther members of their social subsystem have bcen studied intensively for 30 years in the sociological or social-psycholoyicul research tradition. Rogers and Shoemaker, and Rothman offer a series of generalizations that link individual demuglaphic and sorinernnomic characteristics to innovative behavior $[9,10]$. Types of variables considered include age, education, soclal slutus, dogmatis m, attitudes toward $r$ isk, social participation, cosmopolitanism, and exposure to interpcrsonal communication channels. Where more than a few studies (say, more than 10) are involved in supporting a generalization, typically about two-thirds of the studies support the generalization and the remainder do not support it. One would not wish to base a policy or marketing strategy on this or many of the other generalizations without knowing a great deal more about why these studies reach such disparate conclusions, but current theory does not offer more explicit guidance.

The situation is similar in the case of organizational variables. Two major works have organized and synthesized research on organizational features that influence their innovative behavior (both internal development of innovations and adoption of innovations introduced from the outside are included). Hage and Aiken, and Zaltman, Duncan, and Holbek identify organizational characteristics shown in various studies to have influenced their innovative behavior: size, resources, financial health, slack resources, complexity, centralization, formalization, extent of job rotation, leadership change, performance gaps, employment turnover rate, and others [11,12]. A recent, comprehensive literature synthesis lists 23 organizational variables that have been found to affect organizational innovation and the diffusion of innovations among organizations [4]. 
Environmental variables, variables that describe the contexts in which individuals and organizations innovate, of ten are included in studies that attempt to account for either individual or organizational innovation. No particular synthesis or research tradition has focused on environmental variables, though in general the sociological tradition tends to describe interpersonal communication networks and the economic tradition tends to describe the industrial firm's market environment. Organizationally oriented sociologists and political scientists studying innovation tend to describe the community in which the subject organizations reside; e.g., urbanization, industrialization, growth rate, average resident socioeconomic status. Public Affairs Counseling lists 19 environmental variables found to influence innovation diffusion [4]. The list includes the above variables plus others, such as external crises, rate of technological change, expanding market for services or products, political structure, and political culture.

Students of the innovation process have attempted for years to develop a classification system into which all innovations can be placed and which offers a theoretical explanation of the rate of innovation diffusion or the probability that potential adopters will adopt. Dichotomies such as embodied-disembodied, radical-incremental, productprocess, and primary-secondary have been offered in the literature, though none of these has led to the development of broad, explanatory theory. Rogers and Shoemaker list five innovation attributes (relative advantage, compatibility, complexity, observability, trialability) [9], and Mansfield lists four comparable ones (economic advantage, initial uncertainty, initial commitment requirements, rate of reduction of initial uncertainty) [13]. Zaltman, Duncan, and Holbek present 18 attributes; the list includes variables similar to those of Rogers and Shoemaker and of Mansfield, but adds point of origin, efficiency, terminality, reversibility, commitment, impact on personal relationships, and others [12]. Most, if not all, of these attributes are conceived as perceptions by potential adopters rather than as intrinsic features of the innovation whose values do not change. from adopter to adopter. 'l'hough it has been suggested that there exist "adopterindependent" or "primary" attributes of innovations [6,14], critics argue that even something as apparently invariant as cost is perceived quite differently by potential adopters with differing levels of available resources. This question is elaborated in Section 4.0.

To the extent that the generalizations about individual innovators offered by Rogers and Shoemaker (1971) are representative of this aspect of knowledge [9], very little is known about the relative importance of the various factors associated with the innovative behavior of individuals. In the case of the diffusion of industrial innovations, Nabseth and Ray conclude that it is difficult to say how important profitability is relative to other factors [15]; Mansfield acknowledges that personality at tributes, interest, training, and other characteristics of middle management may play a very large role in industrial diffusion [13]. As Eveland, Rogers, and Klepper point out, "The development of models of the innovation process has not kept pace with the interest in the topic" [16]. The statement applies virtually across the board: we know little about the relative weights to be attached to the dozens of potentially significant variables nor even to broad categories of variables such as individual vs. organizational factors, or organizational vs. technological factors. Many studies have sought to determine whether a particular variable or set of variables is associated with innovative behavior, and how strong the association is. While they may have achieved this objective, the range of variables in any particular study is so narrow that generalizations about the relative weights of different classes of variables cannot be derived. Additionally, the comparability of variables across studies is very limited so that, even when the organizations or innovations studied in separate studies are the same, the measures of innovative behavior or of various independent variables frequently differ $[14,17]$. 
Downs and Mohr have accomplished the most thorough diagnosis of the problem, which they label "instability" of findings across different studies [14]. In addition to measurement and variable specification problems, they add that in most analyses of innovation major interaction effects exist among the variables; interactions are changes in the relative weights of independent variables across each decision situation. Thus, to a poor person cost may overwhelm all other factors, but to a rich person considering the same innovation prestige may overwhelm cost. Since interactive models have not generally been employed in the design or analysis of diffusion studies, interaction effects remain buried from view in individual studies but confound effor ts to generalize across them.

\subsection{SUMMARY ASSESSMENT AND CONCLUSIONS}

There is no shortage of variables that have been identified as influencing the innovative peqhavior of individuals and organlzutiviss and, also, the extent and rate of diffusion of innovations. Together they constitute a l'ur'midable 11 st numbering perheps 50 or 60; a summary table of factors influencing innovation and diffusion in the Public Affairs Counseling report includes 78 variables [4]. The 11 terature, thus, latks pursimony; the list of influential variables is unmanageably large whether one's intent is to integrate them into theory or to design a major study that would reduce the list. One problem is that, while concepts such as profitability and uncertainty associated with first use (relative advantage and complexity to the sociologist) span the diversity of disciplinary approaches to diffusion, the measures used to operationalize them and the other variables included in each piece of research do not.

A second problem is model specification-determining which are the key variables and which are surrogates for, or covariates of, others. For example, organizational size and wealth seem to have nu cuisistent relation to innovative hehavior, yet they are almost always included in any study of the correlates of organizational innovation. Downs and Mohr's trenchant critique suggests that size and wealth need to be incorporated differently in analysis [14].

Despite these shortcomings, information can be derived from the diffusion literature that is useful to policy makers. As Downs and Mohr point out,

This is not to say that the body of existing research is useless; when organized properly, when we know just liuw lu examinc it; it may well constitute a powerful source of evidence bearing on important theuretical elements [14].

Sufficient numbers of studies have been done with similar definitions of key variables and within sufficiently restricted situations to enable the findings from such studies to support a moderate level of generalization. These generalizations could be used for policy purposes with some degree of confidence. Rothman drew upon the literature on individual innovativeness to identify a small number of factors that are consistently related to the general propensity to innovate (not the probability of adopting a particular innovation): level of social participation, felt need for change, and socioeconomic status [10]. Hage and Aiken identified a small number of structural features of organizations that are consistently related to the frequency with which social service organizations adopt new programs [11]. Mansfield and others have studied the adoption of successful, incremental, industrial process innovations by firms in competitive environments to an extent that reasonably confident statements can be made about the importance of profitability, uncertainty, and cost for innovation under these restrictive conditions $[13,17]$. 
Beyond these limited situations, the literature offers little generalized knowledge that could be applied directly to the problems facing policy makers. If diffusion research is to bear fruit for this audience, analysts must approach the literature with specific questions in mind and with an understanding of diffusion research methods and concepts. 
THIS PAGE INTENTIONALLY LEFT BLANK 


\section{SECTION 4.0}

\section{COMMUNICATION RESEARCH}

\subsection{INTRODUCTION}

Communication research studies show how information flows from sources to receivers and what factors influence the receptivity to, and use of, information by receivers. Diffusion is that subset of communication research concerned with the transmission of ideas perceived as new by the receivers [9]. Because the messages are new in the case of diffusion, there is a degree of risk for the receiver. The focus on new ideas by diffusion researchers has led to a more thorough understanding of the process of communication. For example, the idea of the flow of communication as a multistep process lacked clear conceptual development until it was probed by researchers studying the diffusion of innovations. Also, the role of different communication channels at various stages in the innovation decision process was masked until students of diffusion found that mass media channels are more important for creating awareness-knowledge of new ideas-while interpersonal channels are more important in changing attitudes toward innovations.

The importance of communication variables is evident in innovation decision-making models in which communication sources and channels are the stimuli to adoption [9]. Such models are abstractions of the cognitive or mental processes that individuals pass through from first knowledge of an innovation to a decision to adopt or reject that innovation and to confirmation of their decisions. Different types of factors are of primary importance to the decision maker at each of these stages of the decision process; communication variables influence the creation of knowledge about an innovation and potential adopters' attitudes toward it.

\subsection{KEY FINDINGS AND GENERALIZATIONS}

Decision making begins when an individual is exposed to the innovation's existence and gains some understanding of how it functions. The predispositions of individuals influence their behavior toward communication messages and the effects such messages are likely to have. Generally, individuals tend to expose themselves to those ideas that are in accord with their interests, needs, or existing attitudes and to consciously or unconsciously avoid messages that conflict with their predispositions. In this problemsolving perspective, it is a need or problem that provides the motivation for some kind of search behavior on the part of individuals $[18, \mathrm{p} .423]$.

Therefore, as the levels of knowledge in the social system increase, the corresponding pressures on individuals to adopt the innovation also increase [19, p. 30]. Knowledge, formulated as messages, flows from the mass media and/or existing adopters to potential adopters in the social system. The receipt of mass media messages depends upon the individual's exposure to the media and the strength of his need for the innovation. The receipt of interpersonal messages depends up on the individual's communication network or social contacts across groups and cliques.' Media messages help make potential adopters aware of an innovation and reduce the resistance of the more innovative persons [5]. The adoption of innovations by less innovative or more resistant individuals is, then, largely dependent upon interpersonal communication from the early adopters of the new ider. 
Diffusion research also has shown that there is a threshold of knowledge in society (at which about 20 percent of the population knows of an innovation) below which little adoption of any innovation is likely to occur. Once this threshold has been reached in the social system as a whole, however, added knowledge produces increasing returns in adoptions. The threshold occurs at about that point where opinion leaders in the social system begin to favor the innovation. These individuals are the key consumers who influence the course of a given innovation and, thus, should direct or be targets of market research and promotional activities to gain adoptions.

Opinion leadership is the ability of certain individuals in a social system to influence other individuals' attitudes and overt behavior in a desired way with relative frequency [9]. Studies focusing upon the personality characteristics of opinion leaders show that they generally have (1) more mass media exposure, (2) higher social status and wealth, (3) more formal education, (4) greater innovativeness, (5) mnre social participation, (6) greater empathy, and (7) are more cosmopolitun than the avcragc member of the sonial system [20, p. 298]. Opinion leaders provide a valuable service to llieii fullowers. Thcy maintain their position in society by being more competent, more accessible, and conforming more closely to the norms of the social system than other individuals. Opinion leaders can help prime the pump of social change by supporting innovations or, on the other hand, they can discourage change by resisting the adoption of new ideas. They may work either for or against a particular innovation.

The innovation decision model also suggests that persuasion takes place before any decision is made concerning an innovation. At this stage, an individual forms a favorable or unfavorable attitude toward the innovation and becomes more psychologically involved with it. The greatest involvement with an innovation occurs when an individual actively seeks information about that Innovation and begins to consider how the innovation can be applied to his own situation or needs [21]. In developing an attitude toward the innovation, the individual may vicariously apply the new idea to his present or anticipated future situation.

Since all new ideas have some degree of subjective risk, individuals are unlikely to bo certain of the innovation's resul ts or cunsequeinces and feel a noed for reinforcement of their attitudes toward the idea. This sort of reinforcement can best be provided by peers via interpersonal channels since mass media messages are too general to confirm an individual's beliefs about an innovation. So, the individual seeks reinforcement from others who are quite likely to be similar in characteristics (status, education, etc.) to himself. Without such confirmation of his beliefs, the individual may never pass beyond the knowledge stage. However, the formation of a favorable or unfavorable attitude toward an innovation does not necessarily lead to direct or immediate adoption or rejection. An individual may linger in any one stage of the innovation decision-making process before moving on. One way to speed up the diffusion and adoption of an innovation, however, is to shorten the decision-making process of individuals by providing the demonstrations and interactions necessary to confirmation of attitudes. Another way is to speed up the creation of awareness knowledge within the social system.

\subsection{SUMMARY ASSESSMENT AND CONCLUSIONS}

Communication research emphasizes and enriches key elements of the diffusion of innovations. The early stages of an individual's decision process, during which awareness 
of the innovation and information about its characteristics, influence the subsequent decision. Several generalizations emerge from the literature that are of interest to persons wishing to influence the rate of diffusion of particular innovations:

- Mass media are more important for creating awareness about innovations than other types of communication channels, while interpersonal channels are more important in changing attitudes toward innovations.

- Knowledge of an innovation spreads ahead of the actual adoption of that innovation. There is a threshold of knowledge about an innovation in a social system below which little adoption is likely to occur. This tends to be about 20 percent of the total population of the social system.

- Opinion leaders play key roles in shaping the attitudes and opinions of their followers about innovations. Opinion leaders possess certain characteristics that make them identifiable members of a particular social system (e.g., they have greater media exposure, higher social status, wealth, and education; greater social participation; and conform more closely to social system norms).

- Interpersonal communication channels are more effective than mass media in overcoming feelings of excessive psychological risk among prospective adopters of an innovation.

These generalizations apply to technologies resembling consumer goods, intended for purchase by individual decision makers. 
THIS PAGE INTENTIONALLY LEFT BLANK 


\section{SECTION 5.0}

\section{MARKETING AND CONSUMER RESEARCH}

\subsection{INTRODUCTION}

Thousands of new products, most of which have been preceded by elaborate product screening, concept testing, product development, and market testing, are introduced into the market each year. Yet, no less than 95 percent fail. In view of this, diffusion research has become vital for better marketing management decisions concerning new product introduction, including pricing, promotion, and distribution strategies. Stated differently, estimates of the rate of adoption or market penetration are highly important to most marketing management decisions concerning the diffusion of new products to target consumer groups.

Marketing and consumer research introduce a set of variables that are controllable by management (that is, the diffusing agent) and generally outside the realm of both "classical" diffusion research and communications research. Emphasis is shif ted to the supply of innovations, strategies for stimulating demand, and the context of the diffusion process [5]. These variables can be designed with the adopter and the perceived innovation characteristics in mind so that a faster adoption rate can be achieved. Marketing variables include "marketing mix" decisions about:

- the product innovation - its basic concept, its position vis-a-vis similar products, features, design, packaging, product line, etc.;

- $\quad$ price - price strategy (skimming or penetration), price differentials, and discounts;

- promotion - personal selling, mass and specialized media, copy, and promotional appeal; and

- distribution - decisions concerning the number and type of distribution outlets through which to sell the innovation.

In recent years marketing management has engaged in sophisticated application of information about adopter variables and innovation attributes to marketing mix decisions to improve the chances that consumers will accept new products.

\subsection{KEY FINDINGS AND GENERALIZATIONS}

Market price is, of course, a key determinant of penetration. Marketing research recognizes the influence that different pricing strategies by firms have on the timing and extent of market penetration as well as on the market segment affected. The learning curve phenomenon, in which average production costs decline as the industry learns to produce more efficiently, is only one factor that influences product price. For example, at the introductory and growth stages of the product life cycle, setting a high price for the product and thus "skimming" the market may be an effective price policy if competition is weak and the high price is, to some extent, a desirable characteristic of the product itself. At later stages of the product life cycle as competitors enter the market, a more competitive price policy must be practiced if sales growth and market share are 
important considerations. Penetration price policy, on the other hand, is designed to set lower prices at the early stage of introducing the innovation so that high sales volume and market share can be achieved rapidly.

Though price reductions may make the new product affordable by a greater number of consumers, reducing social-psychological costs (i.c., risk) is of ten a necessary condition for additional purchases to occur [22]. Therefore, reducing consumer cost frequently requires both financial and nonfinancial cost reduction. Innovations representing dramatic departures from products or techniques they replace (e.g., solar technology) may generate strong demand on the part of innovators and early adopters, for whom price is not a primary consideration. But, price reduction will not necessarily generate demand from other consumers if their nonfinancial costs remain high. Psychologicul costs must be reduced if higher rates of market penetration and innovation adoption are to be achieved. For example, discontinuous innovations such as solur technologies are subject to high performance risks, which translate as high psychologleul custs fur tlie prospective hiryer. There are also financial risks associated with performance in relation to continuing cost. In some cases, high initial cost can posltively influence adoption, suggesting that implied quality or the notion that "the price is the good" is paramount [23]. Yet, high continuing cost for the same technology can be negatively related to adoption. Several social risks are expected to influence the rate of adoption. The consumer may be ridiculed or ostracized by his peers for adopting the innovation. Such risk is particularly significant in the case of products, like solar collectors, whose adoption is easily observable by peers and reference groups. Another social risk is that the new product may take some control from the hands of consumers and possibly generate negative reactions. A basic risk is that consumers do not normally like change unless the change is highly and imminently gratifying.

Variables relating to consumer willingness or abillty to pay psychological costs have been identified by diffusion researchers. Some of these are venturesomeness, social integration, self-confidence in problem solving, self-confidence in psychological matters, family income, and education. Innovation-specific factors associated with consumer readiness to pay psychological costs are derived directly from classical diffusion research and include perceived innovation attributes, such as relative advantage, complexity, trialability, observability, communicability, and perceived risk [9,24].

It is the perceptions of these attributes, not necessarily any intrinsic quality of the innovation itself, which affect the rate of adoption. When the innovation is perceived as incompatible with consumer habits, highly complex and risky, not available for trial on a small scale, and its merits are not easily observable and communicable, a slow adoption rate (as was the case with microwave ovens a decade ago) or innovation rejection takes place. On the other hand, a fast adoption rate occurs when compatibility, observability, communicability, and triability are high, while complexity and perceived risk are low.

Marketing management can exercise limited influence over perceived innovation attributes. Management can find out how consumers perceived the innovation attributes and, subsequently, can design products and promotion strategies to stress product attributes or benefits highly valued by the market segments in question. If consumers perceive solar technology innovations as complex, marketing management may increase the adoption rate by simplifying product design. Stressing those attributes which clearly show that solar technology innovations are superior to conventional alternatives (independence, cleaner environment, etc.) may be an effective marketing approach if consumers do not perceive a clear relative advantage. Demonstrations aimed at opinion leaders, and reinforcing the resulting word-of-mouth and interpersonal communications 
by promotional campaigns in the mass media can be used to increase buyer confidence and awareness.

Consumers who have high sociceconomic status and are venturesome, open minded, risk taking, and cosmopolitan tend to adopt new products faster than other consumers. Although marketing managers cannot influence the above variables, they can take advantage of them to accelerate the rate of adoption. They can do so by designing a marketing mix likely to appeal to the adopting group in mind. One of the paradoxes here is that, in order for an innovation to be successfully introduced to the market, marketing mix must be designed to appeal to the innovators. Yet, in order for the innovation to reach market growth and maturation stages, marketing mix must be changed to appeal to the new target groups: the early adopters, and early and late majorities. The high financial and psychological costs, lack of promotion, and very sparse distribution that characterize solar water and space heating may nevertheless lead to adoption by extremely innovative consumers; but, such marketing mix variables must be changed if adoption by other groups of consumers is desired. Both financial and psychological costs and distribution barriers must be reduced. In addition, promotion strategy should stimulate rapid sales growth.

\subsection{SUMMARY ASSESSMENT AND CONCLUSIONS}

The literature suggests several generalizations that apply to durable consumer goods.

- At early stages in the diffusion process, neither high financial costs nor socialpsychological costs inhibit purchasing decisions. This is because innovators generally are insensitive to price and because social-psychological risks are of ten sought by innovators.

- In later stages of diffusion, the importance of both financial and socialpsychological costs increases. As the price goes down, more consumers can aff ord the product but, unless social-psychological costs are reduced, adoption is less likely to occur. Discontinuous or major innovations impart high psychological costs that, unless carefully dealt with, can reduce the adoption rate significantly.

- Perceived innovation attributes are better predictors of adoption or rejection than socioeconomic or personality characteristics of potential adopters $[24,25]$.

- Through appropriate design of the marketing mix (packaging, pricing strategy, promotion, distribution), management can influence the costs, psychological costs, and perceived attributes of innovations and thereby influence diffusion rates. 
THIS PAGE INTENTIONALLY LEFT BLANK 


\section{SECTION 6.0}

\section{SOLAR ENERGY MARKET PENETRATION MODEIS}

The need for information on the market potential of solar energy technologies has led to the development of several analytical models which project future market penetration. This review focuses on one model developed for DOE by the MITRE Corporation titled A System for Projecting the Utilization of Renewable Resources (SPURR) [26]. SPURR, with the capability to analyze the potential of approximately 30 solar system configurations in four major potential markets, is the most comprehensive solar market penetration model constructed to date. Other solar penetration models are similar in basic structure and approach to SPURR and, thus, the discussion here applies to them as well $[27,28,29,30]$.

The purpose of a market penetration model is to provide a simplified but accurate description of the probable diffusion of a new technology in specific markets. Thus, the complex process of technological change must be reduced to a few essential relationships. The way this simplification is performed has major consequences for the utility of the model for different purposes. SPURR, like other solar penetration models, summarizes in a few parameters the performance of prototype solar systems which are hoped to be typical of systems that could compete in specific markets. The model then estimates the cost of these systems and costs of conventional energy systems servicing the same markets and compares the costs. An "S-shaped" market-share curve is used to project the share of a potential market that each candidate system will achieve in future years.

Market shares for specific solar energy systems are predicted by SPURR using a "figure of merit" for each system and each market. The figure of merit is intended to approximate the relative attractiveness to the consumer of alternatives. The exact parameters of the figure of merit differ from market to market. In all cases, however, cost is the major factor determining the figure of merit for a particular system in a particular market, and it is the driving force behind the penetration projections. For example, in the SPURR Industrial Process Heat (IPH) sector, life-cycle cost is the only factor used in the figure of merit. Cost is of ten the dominant factor in the choice between alternative energy systems but, as the diffusion research described in other sections of this paper shows, many other factors also influence the rate of diffusion. For this reason, the existing mix of fuels used for IPH cannot be explained by comparison of life-cycle costs alone. Since the SPURR model of market acceptance cannot reproduce the existing mix of fuels, its predictions of future mix (including solar energy) must be considered arbitrary. Generally, solar market penetration models use the S-shaped curve to relate some indicator of economic feasibility to market penetration. The validity of solar market penetration models is highly questionable because there is very little empirical infor mation to support this latter rclationship [31].

Two studies, one by RUPI Inc. and another by Jerome Scott, approached the solar market penetration problem differently $[32,33]$. These studies used consumer survey techniques to estimate buyer responses to various economic and technical comparisons between solar and conventional energy sources. Market penetration models based on consumer response data could lead to a better understanding of consumer attitudes toward the purchase of solar energy systems and thereby increase confidence in assessment of the market response to solar energy. But, use of consumer response data presents its own set of methodological problems. There is of ten a divergence between responses given in a 
survey to hypothetical situations and actual decisions on the purchase of a solar system. Also, such studies have difficulty making predictions that account for changing conditions over time.

Solar market penetration models have been used for program planning purposes because they are viewed as able to produce results. However, little effort has been devoted to the problem of how results should be interpreted. Market projections by themselves offer little basis on which program decisions can be made. To be used as a program planning tool, the response of the market to the program must first be examined and understood. Next, an assessment of the benefits of these impacts needs to be made. Market penetration and energy production, by themselves, are inadequate measures of the benefits of a program. These market impacts must be translated into a broader assessment of benefits which cān be used to compare the value to soclety of allerilutive prngram options.

Market penetration models are only useful in examining the attractiveness of certain types of programs. For example, none of the models explicitly treats the R\&D process. Base values for system cost and performance must be entered as input parameters (the models of ten modify these inputs by experience and escalation). Thus, if one wishes to explore the consequence of increased $R \& D$ effort on a technology, an estimate must be made outside the model of the impact of the effort on delivered system capabilities. Models are more capable of estimating the costs and benefits of a market incentive, which reduces each user's costs. The validity of these estimates, however, is only as good as the descriptions of the adoption process built into the model. Where factors other than cost are important, as they are with many new and discontinuous innovations such as solar technologies, market penetration models are likely to produce highly inaccurate or misleading résults.

Programs directed toward reducing noncost barriers to adoption, such as information and demonstration programs, cannot yet be assessed by market penetration modeling. The method or data base by which the impacts of these kinds of programs can be translated into market acceptance is not available. Other types of diffusion research described elsewhere in this paper promise to improve the understanding of market dynumies, which could lead to an improved ability to estimate future market developments. 


\section{SECTION 7.0}

\section{APPLICATIONS OF DIPFUSION RESEARCH TO SOLAR ENERGY POLICY DECISIONS}

\subsection{ALLOCATION OF R\&D BUDGETS}

Budget allocation decisions commonly involve ranking alternative $R \& D$ programs or technologies according to their expected social benefits. Expected benefits are based largely on estimates of the contribution each technology will make to social values, such as cost savings, energy savings, fossil fuel displacement, and reduced environmental degradation. The magnitude of each of these values for a given technology is determined by the extent to which the technology is expected to diffuse and penetrate its market. Estimates of the extent of diffusion tend to be based either on informed guesswork by persons knowledgeable about the technology and its proposed market, or on the basis of simple market penetration models whose parameters are determined largely by cost comparisons between the subject technology and its competitors. As we have seen, market penetration models used for energy technologies have serious shortcomings. Diffusion research offers the possibility of improved market penetration estimates for particular technologies.

Though no existing general theory can predict the influence that cost will have on adopter decisions relative to other factors such as performance or convenience in particular markets, numerous diffusion studies have produced findings on this question. Provided the technology and expected market are specified, the diffusion literature contains findings pertinent to market penetration estimates. Exact counterparts in the literature for an energy technology of interest to government will not be found, but in many cases analogies can be drawn that will lead to greatly improved estimates of the rate and extent of market penetration. In addition, diffusion research offers an approach (i.e., methodologies and conceptual models) for developing new data on the characteristics of markets and potential adopters which could improve descriptions of how future markets might operate and increase confidence in market penetration forecasts. With such tools, researchers can obtain market penetration estimates for particular energy technologies superior to those available using other estimation techniques. Best results will be obtained with technologies that most resemble consumer products and in which individual buyers make the purchasing decisions. Examples might be small wind machines, decentralized photovoltaics, passive design, and fuel cells. The diffusion literature is not as rich in generalizations on industrial innovations, though the considerable research on the diffusion of process innovations among industrial firms is directly applicable to industrial process heat technologies. Other types of adopting units, such as utilities (organizations) and local governments (collectivities), present greater difficulties because of the limited number of relevant diffusion studies available and because of the greater complexity of decision processes in such units. However, diffusion approaches have been employed fruitfully to study these organizations' adoption behaviors and could be used to collect new data to estimate the diffusion of solar ther mal technologies.

\subsection{ASSISSMENT OF ALTERNATIVE INTERVENTION STRATEGIES}

Once a decision is made to use government resources to accelerate the development and application of a technology, a variety of strategies may be employed: $R \& D$, 
demonstrations, regulation, market restructuring, government procurement, tax incentives or other subsidies. The choice of strategy depends upon:

- the nature of the "problem" that government action is intended to ameliorate (noncompetitive cost and performance, lack of information among potential buyers, institutional barriers, attitudes and value preferences among potential buyers);

- the probabillty that each strategy will be effective; and

- the net social benefits of alternative strategies.

Diffusion research seeks to identify factors that influence adopter decisions and, therefore, can help policy mukers determine the nature of the problem that government action is intended to solve. In the case of solar heating and cuuling technolugies, for example, it is not clear whether high first cost rather than lack ol Inl'urilualiun anlluil' potential buyers, inadequate warranty protection, or the complexity of the technology itself is the major problem.* Market and communication studies can help determine whether the "threshold" of knowledge about solar technologies has been achieved among potential buyers; if it has not, cost-reducing strategies would be ineffective and possibly unnecessary. If lack of information about the technology's performance is a major problem, information-producing actions such as demonstrations are called for. In addition, the communication literature provides a framework for characterizing information flows in the market sector of interest. This knowledge can illuminate decisions on whether a demonstration program will be effective and on the optimum number and location of demonstrations. The literature offers the best guidance for technologies such as solar hot water heating and passive design where individuals decide to adopt or reject a new technology. We know the conditions under which mass media works better than interpersonal communication and, in a given murket, we can identify the number and types of people likely to be opinion leaders (and, thus, appropriate targets for demonstration efforts).

There is less evidence from diffusion research when industrial firms, utilities, or government units make a decision to adopt but, if applied to particular market segments, the diffusion approach can yield new data that will help energy policy makers choose the most effective strategy for increasing diffusion rates in these sectors as well. The diffusi on approach, however, is not appropriate for identifying problems associated with the production rate or production costs of energy technologies (i.e., technology supply problems).

*Pilot states in the Energy Extension Service report that uncertainty about the performance of the technology, shortages of materials and supplies, and inadequate skills and labor are as significant a barrier to adoption of energy-conserving technologies as high costs of the technology, lack of capital, and loan interest rates [34]. 


\section{SECTION 8.0}

\section{SUMMARY AND RECOMMENDATIONS}

This overview and assessment of diffusion-related research illustrates that the diffusion of innovations is an extremely complex phenomenon, one not subject to quick understanding through simple generalizations. Policy decisions that rest directly or indirectly on knowledge of diffusion processes, therefore, need to guard against oversimplification; the risk of major inaccuracies is large. Diffusion research not only reveals the complexity of diffusion, but also yields limited generalizations that can be applied to policy questions concerning estimates of future market success of solar energy technologies and to analyses of the effectiveness of programs intended to promote solar energy adoption.

Investigations of diffusion-how new ideas, practices, and products diffuse among a population and why individual members of the population decide to adopt or reject themhave contributed to knowledge about:

- Individual adopter decision processes - what influences act upon an individual as he or she learns about an innovation, is persuaded or dissuaded by the innovation's characteristics, and decides to adopt or reject it?

- Influences on individuals and organizations - how do the characteristics of persons and organizations, the environments in which they function, and the characteristics of innovations themselves affect the likelihood that an individual or organization will adopt an innovation?

- Diffusion rates and patterns - what factors influence how rapidly an innovation diffuses among a population and what the geographic pattern is of diffusion?

- Characteristics of innovators - what kinds of people and organizations are more likely to adopt an innovation; how do they influence other potential adopters?

- The role of information in diffusion - under what conditions are mass media and interpersonal communications effective in promoting increased diffusion?

On the whole, diffusion research has not generated predictive theory or broad generalizations that answer the above questions for a variety of conditions (e.g., different types of innovations, potential adopters, or markets). For example, we do not know in general the conditions under which noncost features of an innovation are more important than cost as determinants of diffusion rate. Nonetheless, the diffusion literature does offer answers to these questions in a number of limited situations, such as the innovative behavior of individuals, a wide range of consumer-durable goods, new programs in social service organizations, and incremental industrial-process innovations among firms in competitive environments.

The literature also is a rich and useful source of information that, if approached properly, can be applied readily to solar energy policy problems. Diffusion researchers have told us what data to collect and how to collect them; they have shown us how to 
analyze the data to learn about how and why diffusion occurs. In a short period, perhaps several months, persons familiar with the diffusion literature can extract information on:

- the factors that will affect the diffusion or market penetration of a particular technology,

- the relative importance of these factors for the population of potential buyers or consumers, and

- the time required for a technology to penetrate or diffuse to a specific proportion of potential buyers.

This information can be used to develop estimates of market penetration in analyses of alternative $R \& D$ budget levels for energy technologies expected to be commercialized in the future. We believe that estimates so derived would be more accurate and reliable than those now employed in energy market penetration modeling. The information also can be used to design effective strategies for accelerating solar energy technology diffusion. Diffusion methods and concepts are designed to identify fundamental imperfections or problems in markets that may be amenable to remedial government action: subsidies, demonstration programs, information dissemination, or R\&D. To the extent that government assumes the posture of a firm promoting a product, marketing mix decisions-those involving product features and packaging, pricing strategy, promotion, and distribution-can be tailored to maximize appeal to various categories of consumers.

In the short term, SERI should demonstrate the value of diffusion approaches and research for improved market penetration estimules using a small numbor of solar energy technologies. Best estimates would be obtained for technologies, such as home solar hot water, space heating, or small wind systems, where individuals are the decision makers, but organizational adopters such as utllltles ulsu should be cxplorod in such a pilnt eff nrt.

For the longer term, in parallel with the shorter term efforts, support of more fundamental investigations of diffusl on und uraiket penctration is recommenres in order to develop improved models of the phenomena that will lead to more accurate estimates of the market penetration of energy technologies and more effective commercialization strategies. By grounding market penetration estimates and commercialization strategies in better social and behavioral theories-theories based on additional empirical studies of diffusion phenomena-the quality of policy decisions using these estimates will be greatly improved. 


\section{SECTION 9.0}

\section{REFERENCES}

1. Rogers, Everett M.; Williams, Linda; West, Rhonda. Bibliography of the Diffusion of Innovations. Stanford, CA: Institute for Communication Research; 1977.

2. Radnor, Michael; Feller, Irwin; Rogers, Everett M. The Diffusion of Innovations: An Assessment. Evanston, IL: Northwestern University; July 1978.

3. Baer, Walter; Conover, C. J.; Cook, Cheryl; et al. Analysis of Federally Funded Demonstration Projects: Supporting Case Studies. Rand Corporation; April 1976.

4. Public Affairs Counseling. Factors Involved in the Transfer of Innovations: A Summary and Organization of the Literature. Washington: U.S. Department of Housing and Urban Development; HUD-PDR-157; August 1976.

5. Brown, Lawrence A. The Innovation Diffusion Process in a Public Policy Context. Columbus, OH: Department of Geography, The Ohio State University; 1978.

6. Kelly, Patrick; Kranzberg, Melvin. Technological Innovation: A Critical Review of Current Knowledge, Vol. I. Georgia Institute of Technology; 1975.

7. Yin, Robert K. Organizational Innovation: A Psychologist's View Revised. Paper prepared for workshop, "Assessment of Current Developments in the Diffusion of Innovations." Evanston, IL: Northwestern University; January 1978.

8. Havelock, Ronald G. Planning for Innovation through Dissemination and Utilization of Knowledge. Ann Arbor, MI: Center for Research on the Utilization of Scientific Knowledge, University of Michigan; 1969.

9. Rogers, Everett M.; Shoemaker, F. Floyd. Communication of Innovations: A CrossCultural Approach. New York: The Free Press; 1971.

10. Rothman, Jack. Planning and Organizing for Social Change: Action Principles from Social Science Research. New York: Columbia University Press; 1974.

11. Hage, Jerald; Aiken, Michael. Social Change in Complex Organizations. New York: Random House; 1970.

12. Zaltman, Gerald; Duncan, Robert; Holbek, Jonny. Innovations and Organizations. New York: Wiley; 1973.

13. Mansfield, Edwin. Industrial Research and Technological Innovation. New York: Norton; 1968.

14. Downs, George W.; Mohr, Lawrence B. "Conceptual Issues in the Study of Innovation." Administrative Science Quarterly. vol. 21: pp. 700-714; 1976.

15. Nabseth, L.; Ray, G. F. The Diffusion of New Industrial Processes. Cambridge: Cambridge University Press; 1974. 
16. Eveland, J. D.; Rogers, Everett M.; Klepper, Constance. Innovation Process in Public Organizations. Ann Arbor, MI: Department of Journalism, University of Michigan; March 1977.

17. Warner, Kenneth. "The Need for Some Innovative Concepts of Innovation: An Examination of Research on the Diffusion of Innovations." Policy Sciences. vol. 5: pp. 433-451; 1974 .

18. Havelock, Ronald G. "What Do We Know from Research about the Process of Research Utilization?" Ideal Systems for Research Utilization: Four Alternatives. Ann Arbor, MI: Institute for Social Research, University of Michigan; 1974.

19. Midgley, David F. Innovation and New Product Marketing. New York: John Wiley and Sons; 1977.

20. Rogers, Everett M. "Mass Media and Interpersonal Communication." Ithiel de Sula Pool and Wilbur Schramm. Handbook of Communication. Chicago: Rand MeNally; 1973; pp. 290-310.

21. Havelock, Ronald G. Planning for İnnovation through visseminalion dud Ulilization of Knowledge. Ann Arbor, MI: Institute for Social Research, University of Michigan; 1971 .

22. Zaltman, Gerald; Stiff, Ronald. "Theories of Diffusion." Scott Ward and Thomas Robertson, eds. Consumer Behavior: Theoretical Sources. Englewood Cliffs, NJ: Prentice Hall, Inc.; 1973; pp. 416-468.

23. Fliegel, F. C.; Kivlin, J. E. "Attributes of Innovations as Factors in Diffusion." American Journal of Sociology. vol. 72: pp. 235-248; 1966.

24, ostlund, Lyma! E. "Perceived Innovation Attributes as Predictors of Innovativeness." Journal of Consumer Research. vol. 1: pp. 23-29; Septembel 1974.

25. Ostlund, Lyman E. "Identifying Early Buyers." Journal of Advertising Research. vol. 12: pp. 25-30; April 1972.

26. Metrek Division, Mitre Corporation. A System For Projecting the Utilization of Renewable Resources: SPURR Methodology. McLean, VA: Mitre Corp.; September 1977.

27. Arthur O. Little, Inc. Solar Heating and Cooling of Building's Commercialization Report: Part B, Analysis of Market Development. Cambridge, MA: Arthur 0 . Little; September 1977.

28. Petersen, H. Craig. Impact of Tax Incentives and Auxiliary Fuel Prices on the Utilization Rate of Solar Energy Space Conditioning. Logan, UT: Utah State University; January 1976.

29. Energy and Environmental Analysis, Inc. The Market-Oriented Program Planning System: Industrial Sector Methods and Results. Prepared for Energy Research and Development Administration; 1977. 
30. SRI International. A Comparative Evaluation of Solar Alternatives: Implications for Federal R\&D. Report to Solar Working Group, U.S. Department of Energy; 1978.

31. Schiffel, Dennis; ,Costello, Dennis; Posner, David; Witholder, Robert. The Market Penetration of Solar Energy: A Model Review Workshop. Golden, CO: Solar Energy Research Institute; January 1978.

32. RUPI, Inc. Federal Incentives for Solar Houses: An Assessment of Program Options. Prepared for U.S. Department of Housing and Urban Development; July 1972.

33. Scott, Jerome. Solar Water Heating: Economic Feasibility, Capture Potential and Incentives. Prepared for National Science Foundation; February 1977.

34. Energy Extension Service, U.S. Department of Energy. Summary of Barriers to Energy Conservation Reported by the Pilot States, First Two Reporting Periods. Washing ton: U.S. DOE; 1978. 
THIS PAGE INTENTIONALLY LEFT BLANK 
No. of Copies

1

1

1

1

1

1

1

1

1

1

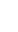

1

1

1

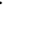

$\underline{\text { Distribution }}$

Department of Energy:

DOE, SERI Site Office

Contracting Officer

Attn: Charles M. Skinner

Chicago Operations Office

Interim Program Division

Attn: M. E. Jackson

Division of Solar Technology

Office of Asst. Director

for Administration

Attn: R.H. Annan

Office of Asst. Secretary for Conservation \& Solar Applications

Attn: R. Scott

Office of Solar, Geothermal, Electric \& Storage Programs

Attn: Martin Adams

Division of Energy Technology

Administration

Attn: S. Hansen

Division of Distributed

Solar Technology

Office of the Director

Attn: R. San Martin

Division of Central Solar

Technology

Office of the Director

Attn: H. Coleman

Division of Energy Storage

Systems, ETS

Officc of the Director

Attn: G. Pezdirtz

Division of Planning \& Energy

Transfer, ETS

Office of the Director

Attn: Leslie Levine

Wind Energy Systems

Attn: L. Divone 